\title{
Cannibalism and intraguild predation involved in the intra- and inter-specific interactions of the invasive fall armyworm, Spodoptera frugiperda (Lepidoptera: Noctuidae) and lepidopteran maize stemborers
}

Bonoukpoe Mawuko Sokame ( $\sim$ jsokame@gmail.com )

International Centre for Insect Physiology and Ecology https://orcid.org/0000-0001-5874-3243

Bonoukpoè Mawuko Sokame

International Centre for Insect Physiology and Ecology

Boaz Musyoka

International Centre for Insect Physiology and Ecology

Samira A. Mohammed

International Centre for Insect Physiology and Ecology

Amanuel Tamiru

International Centre for Insect Physiology and Ecology

Anani Bruce

International Maize and Improvement Centre

Peter Anderson

Swedish University of Agricultural Sciences: Sveriges lantbruksuniversitet

Green K. Karlsson

Swedish University of Agricultural Sciences: Sveriges lantbruksuniversitet

Paul-André Calatayud

International Centre for Insect Physiology and Ecology

\section{Research Article}

Keywords: Spodoptera frugiperda, cannibalism, stemborers, intraguild predation, Intra- and interspecific interactions

Posted Date: February 14th, 2022

DOI: https://doi.org/10.21203/rs.3.rs-1306705/v1

License: (a) This work is licensed under a Creative Commons Attribution 4.0 International License.

Read Full License 


\section{Abstract}

Intra- and interspecific competitions play important role in determing spread and survival/death (cannibalism or intraguild predation) of organisms which share the same resource. However, the trends of relation between cannibalism and intraguild predation, and the costs and benefits of such behaviours are difficult to establish within insect communities and a little is known about how such behaviours are affected by invasive species. The present study was aimed at assessing the interactions between larvae of fall armyworm (Spodoptera frugiperda) and maize stemborers (Busseola fusca, Sesamia calamistis and Chilo partellus) in relation to cannibalism and intraguild predation when they are subjected to utilize the same resource. Experiments involving treatments with either single species of $S$. frugiperda or any of the stemborers or pairwise species combinations were conducted under laboratory conditions. The experimental insect larvae were reared on maize leaves and monitored until the last developmental stage where larval survival, mortality, and cannibalism and/or intraguild predation were recorded. Results of the intra-specific interaction indicated that $S$. frugiperda exhibited cannibalism to a larger degree than the stemborers species, especially at the late instars stages. The higher cannibalism trait in S. frugiperda turned however to competitive advantage as it led to a higher degree of intraguild predation when they cohabit with other stemborer species. Overall, interaction with $S$. frugiperda is thus detrimental for the stemborer species and may be an important factor to explain the invasive success of the pest. Such knowledge is essential in designing successful integrated pest management strategies.

\section{Key Message}

- Understanding the intraguild interactions between pest species with overlapping ecological niches is crucial to predict the impact they will have on species abundance and competitive displacement

- Invasive fall armyworm co-inhabits maize with stemborer species in maize cropping systems.

- The higher cannibalism trait in fall armyworm larvae turned into competitive advantage as it led to a higher degree of intraguild predation when they cohabit with stemborer species

- The higher intraguild predation of fall armyworm on stemborers may impact population dynamics and niche displacement in maize

\section{Introduction}

Resource availability varies spatially and temporally either within or across developmental stages and competitive exclusion should result when resources are limited. Such exclusion depends on the biological characteristics of the interacting organisms, where some species may have better competitive abilities. Intra- and interspecific competitions play an important role in determing survival/death and spread of organisms which share the same niche (Cameron et al. 2007; Gurevitch et al. 1992). The interaction between organisms can be expressed as either exploitative (as use of the resource by one species reduces the availability for the other) or interference competition (when one competing species behaviourally restricts the other species from access limited resources supplies). In the most extreme 
form of interference competition, the interaction leads to the death of one of the involved organisms and could be defined as a form of either cannibalism or intraguild predation.

Cannibalism, also called intraspecific predation, is known as killing and consumption of a conspecifics (Richardson et al. 2010) and is a widespread behaviour in phytophagous insects, mostly in lepidopteran species (Richerdson et al. 2010). It is often favored under high population densities (Sokame et al. 2022) and when resources are limited (Elgar \& Crespi 1992) but can occur even when food is not limited (Polis 1981). Intraguild predation (IGP) occurs between different species within the same trophic level (Bentivenha et al. 2016a). Polis \& Holt (1992) reported that although combining elements of predation and competition, intraguild predation is distinct from competition because one participant (the predator) accrues immediate energetic gains. It is also distinct from classical predation, because the act reduces potential competition besides the actual energetic gains. Intraguild predation can act as mechanisms of population regulation or as determinants of community structure in phytophagous insect communities (Holt \& Polis 1997; Bentivenha et al. 2016a; 2017). Irrespective of whether it is cannibalism or intraguild predation, these behaviours are costly in terms of energy, time, risk of injury and death (Briffa \& Elwood 2004; Kelly \& Godin 2001) for competing individuals that may have repercussions for an individual's fitness. The balance between cannibalism and intraguild predation depends on involved species. For instance, it was reported that intraguild predation is less frenquent than cannibalism for coccinellid species Ciccinella spetempunctata L. and Hippodamia convergens Guerin-Meneville as compared to the predatory bug Geocoris bullatus Say when cannibalism versus intraguild predation was compared among the three species (Takizawa \& Snyder 2011). Furthermore, Rasekh \& Osawa (2020) reported that two coccinellid species Harmonia axyridis and $H$. yedoensis were exposed to either cannibalism or IGP, and $H$. axyridis had longer development time while $H$. yedoensis presented shorter development and lighter adult weight. Therefore, the trends of relation between cannibalism and intraguild predation, and the costs and benefits of such behaviours is difficult to establish. Moreover, there is still little known about how such behaviours are affected by invasive species and how such that could affect crop pests that share the same resources.

In East and Southern Africa, the noctuid stemborers, Busseola fusca (Fuller) and Sesamia calamistis Hampson, and the crambid Chilo partellus (Swinhoe) are key pests of maize and sorghum (Seshu-Reddy 1998; Kfir et al. 2002). Depending on altitude they occur as single species or mixed multi-species communities (van den Berg et al. 1991; Tefera 2004; Ong'amo et al. 2006; Krüger et al. 2008). In addition to these maize pests, the recently introduced Fall Armyworm (FAW), Spodoptera frugiperda J.E. Smith (Lepidoptera: Noctuidae), which was detected in sub-Saharan Africa in 2016 (Goergen et al. 2016) and thereafter spread quickly in Africa (De Groote et al. 2020; Kassie et al. 2020), is currently sharing the same maize plant feeding guild as the pre-existing lepidopteran stemborers (De Groote et al. 2020; Sokame et al. 2020; Goergen et al. 2016). The stemborer larvae feed on young leaves until the third instar from where they bore into the maize stems and then feed from them (Holloway 1998; Polaszek 1998); whereas FAW larvae feed only on leaves throughout their development, especially the central leaves in plant whorl (Morrill \& Greene 1973; Van den Berg 1997; Montezano et al. 2018). In addition, in maize fields at tasseling stage, the FAW larvae could be found feeding on the tassels and subsequently on the 
ear, silk, cob, and even in stemborer holes in the plant stem (CAB International 2017; Morrill \& Greene 1973; Cruz and Turpin 1982) leading them to share the same ecological niche with possible intraguild competition. A previous study reported competition among these four maize pests when they utilize the same resource in a restricted space (Sokame et al. 2020) and the decrease of stemborer density at maize reproductive stage in maize fields following the invasion of FAW in the system (Sokame et al. 2021a) indicates competitive exclusion by FAW since its introduction in Africa. However, the potential of cannibalism and intraguild predation within the community is not well known.

Cannibalism and intraguild predation could contribute to FAW rapid establishment and for interactions in these maize lepidopteran pest communities. In the native range of FAW, cannibalism has been reported (Chapman et al. 1999b; Andow et al. 2015) as well as intraguild predation between FAW and Helicoverpa zea (Bentivenha et al. 2016a). Cannibalism has also been reported in C. partellus, but only at high larval densities (Bonhof \& Overholt 2001). Nevertheless, there is still much to be clarified about the behaviour of the other stemborer species, and interspecific interactions between FAW and these stemborers when they co-occur and the fast and successful establishment of FAW in Africa. A better understanding of the intraand interspecific interactions will be useful to understand how competitive displacement occurs between those pest species sharing a given ecological niche, and consequently might help to enhance designing successful integrated pest management strategies (Benelli 2015). In this context, the present study aimed at assessing the potential of cannibalism and intraguild predation of the four lepidopteran maize pests species when they are subjected to utilize the same resource and if this can lead to competitive exclusion.

\section{Materials And Methods}

\section{Insects}

The stemborer and FAW larvae were provided by the Animal Rearing and Containment Unit (ARCU) at icipe, Nairobi, Kenya. Larvae were reared on artificial diet in cylindrical plastic jars $(16.5 \mathrm{~cm}$ high and $9 \mathrm{~cm}$ in diameter) with about $200 \mathrm{ml}$ of diet per jar. After inoculation, the plastic jars were tightly sealed using perforated lids with galvanized mesh. They were covered with tissue paper and kept in a rearing room at $26 \pm 1^{\circ} \mathrm{C}, 60 \pm 5 \% \mathrm{RH}$., and L12 and D12 photoperiod. Twice a year, each colony was rejuvenated with field-collected stemborer or FAW larvae. All insect laboratory rearing was carried out at $25 \pm 2{ }^{\circ} \mathrm{C} ; 50-70 \%$ $\mathrm{RH}$ and a photoperiod of 12:12 (L:D) h.

\section{Experimental Set Up}

Experiment 1: Cannibalism and intraguild predation involved in fall armyworm and stemborer species larval age-grouped pairing communities

To understand the potential of cannibalism and intraguild predation, an experiment was settled involving treatments with either single species of FAW or any of the stemborers (B. fusca: Bf, S. calamistis: Sc and C. partellus: $\mathrm{Cp}$ ) or pairwise species combinations between FAW and each of the stemborers. The 
experiments were conducted in plastic containers $(16 \mathrm{~cm} \times 10 \mathrm{~cm} \times 7 \mathrm{~cm})$ lined with a paper towel to absorb excess moisture containing 6 pieces of freshly cut maize leaves $(10 \mathrm{~cm} \times 6 \mathrm{~cm})$. The larval instars were structured in three age groups: neonate to second as small size, third to fourth as medium size and fifth and sixth instar as large size. The single-species infestation treatments consisted of 40,20 and 10 larvae for small, medium, and large size groups, respectively. Those densities were chosen as these densities are usually encountered in the field (Sokame BM. Pers. Obs.). Similar to the method of Bonhof \& Overholt (2001) to assess cannibalism between stemborer species, the pairing-species combination involved 20, 10 and 5 larvae per container of each species for FAW+Bf, FAW+Sc and FAW+Cp pairings for each small, medium and large size group, respectively (Table 1). The survival, relative growth rate, mortality (dead larvae found in full corpse), and cannibalism coupled with intra-guild predation (dead larvae found in partial corpse or disappeared corpse) were recorded four (4) days after the settlement (corresponding to the mean time from one instar to another until L5 for FAW) and after five (5) days from L5 to L6, the last instar for pupation.

Table 1

Number of larvae used for each species in the single- and multiple-species combinations tested for each of the three densities of infestation.

\begin{tabular}{|c|c|c|c|}
\hline \multirow[t]{2}{*}{ Combinations } & \multicolumn{3}{|c|}{ Larval sizes } \\
\hline & Small & Medium & Large \\
\hline FAW & 40 & 20 & 10 \\
\hline $\mathrm{Bf}$ & 40 & 20 & 10 \\
\hline Sc & 40 & 20 & 10 \\
\hline Сp & 40 & 20 & 10 \\
\hline $\mathrm{FAW}+\mathrm{Bf}$ & $20+20$ & $10+10$ & $5+5$ \\
\hline $\mathrm{FAW}+\mathrm{Sc}$ & $20+20$ & $10+10$ & $5+5$ \\
\hline$F A W+C p$ & $20+20$ & $10+10$ & $5+5$ \\
\hline
\end{tabular}

Experiment 2: Cannibalism and intraguild predation involved in fall armyworm and stemborer species larval life-time pairing communities

To check if cannibalism or intraguild predation continues in all instars and whether individuals that have fed on conspecifics gain some advantages, a second experiment was conducted. It involved single species infestation of either fall armyworm (FAW) or any of the stemborers (B. fusca: Bf, S. calamistis: Sc and $C$. partellus. $\mathrm{Cp}$ ) larvae and pairwise multi-species infestation of FAW and stemborers was settled with larval neonate instar. The single-species infestation treatments consisted of 20 neonates while the pairing-species combination involved 10 neonates of each species per container. The same parameters 
as described in experiment 1 above were evaluated from neonate to the last instar larvae for pupation with four (4) days interval.

For both the experiments after the infestation, plastic containers were closed with perforated plastic lids until the experiment terminated. The insects in the container were kept in a rearing room at a temperature of $25 \pm 0.05^{\circ} \mathrm{C}, \mathrm{RH}$ of $58.5 \pm 0.4 \%$, and a photoperiod of L12:D12. Each treatment was replicated twenty times. Like the method of Bonhof \& Overholt (2001), after 4 days, containers were opened to record the number of surviving larvae (Ns) and the number of dead larvae (Nd) of each species. The cannibalism (C) in single-species communities and both cannibalism and intraguild predation (C\&IGP) in multi-species communities were calculated as follow:

$$
\operatorname{Cor}(C \& I G P)=N-(N s+N d)
$$

Where $\mathrm{N}$ denoted the initial number of larvae inoculated in each container.

The relative growth rate (RGR) for each species was calculated using the following equation (Ojeda-Avila et al., 2003):

$$
\mathrm{RGR}=\frac{\text { Masspersurvivinglarva }- \text { Initialmassperlarva }}{\text { Numberofdaysafterpairingspecies }}
$$

\section{Data Analyses}

The number of surviving larvae, the number of dead larvae and the number of larvae that have been consumed (cannibalism and intraguild predation) from either experiment 1 or experiment 2, were analysed using a generalized linear model (GLM) with negative binomial procedure. Significant differences were separated using Tukey's multiple comparison test performed using the R package "Ismeans" (Lenth 2016). The relative growth rate (RGR) of the larvae from the two experiments were analysed using Kruskal-Wallis nonparametric procedure with dunn.test $\mathrm{R}$ package after being tested for normality and homogeneity of variance using Shapiro-Wilk and Bartlett tests, respectively. All analyses were performed with $\mathrm{R}$ software version 3.5.1 (R Core Team 2018).

\section{Results}

\section{Survival, mortality, and cannibalism of fall armyworm and stemborers in single-species combination}

At small larval size, FAW had the lowest survival rate while $B$. fusca had the highest $(\mathrm{LR}=26.38, \mathrm{df}=3 ; \mathrm{P}$ $\leq 0.0001)$. At medium larval size group, no significant difference was recorded between the four species $(L R=3.01, d f=3 ; P=0.39)$ while at large larval size group, the survival rates of the three stemborer species were significantly higher than those of FAW $(L R=31.66, d f=3 ; P \leq 0.0001)$ (Fig. 1A). Between larval size groups for a given species (Fig. 1A), the survival rate of FAW was significantly lower at large 
size group as compared to the smaller size groups $\left(\chi^{2}=22.30 ; d f=2 ; \mathrm{P} \leq 0.0001\right)$ in opposition to $C$. partellus where higher survival rate was recorded at larger size group $\left(\chi^{2}=16.45 ; d f=2 ; P \leq 0.0001\right)$. For $B$. fusca, survival rate was significantly low at medium size group as compared to small and large size groups $\left(\chi^{2}=6.72 ; d f=2 ; P=03\right)$ while no significant difference was recorded between $S$. calamistis larval sizes $\left(X^{2}=5.30 ; d f=2 ; P=0.07\right)$.

In terms of mortality (Fig. 1B), there was no significant difference between the four species at small larval size group $\left(X^{2}=7.57 ; d f=3 ; P=0.06\right)$. However, at medium size group, $B$. fusca presented a significantly higher mortality rate than FAW $\left(\chi^{2}=22.23 ; \mathrm{df}=3 ; \mathrm{P} \leq 0.0001\right)$, while at large size group, $C$. partellus mortality was significantly lower as compared to FAW and B. fusca $\left(X^{2}=25.37 ; \mathrm{df}=3 ; \mathrm{P} \leq 0.0001\right)$. Between larval size groups for a given species, large size of FAW presented a significant higher mortality as compared to small and medium size groups $\left(\chi^{2}=16.62 ; \mathrm{df}=2 ; \mathrm{P} \leq 0.0001\right)$. The mortality rates of $B$. fusca were significantly higher at medium and large size groups than at small size group $\left(\chi^{2}=5.17\right.$; $\mathrm{df}=$ $2 ; \mathrm{P}=0.04)$ while they were significantly higher at small and medium size groups than large size group for $C$. partellus $\left(\chi^{2}=12.25 ; d f=2 ; P \leq 0.0001\right)$. No significant difference was revealed between the different size groups of $S$. calamistis $\left(\chi^{2}=1.45 ; \mathrm{df}=2 ; \mathrm{P}=0.48\right)$.

The cannibalism rate (Fig. 1C) was significantly more pronounced in FAW than in stemborer species at all larval size groups, small $\left(X^{2}=58.76 ; d f=3 ; P \leq 0.0001\right)$, medium $\left(X^{2}=46.63 ; d f=3 ; P \leq 0.0001\right)$ and large size $\left(X^{2}=105.61 ; d f=3 ; P \leq 0.0001\right)$. On the other hand, while the higher cannibalism rate of FAW was recorded at large size group $\left(\chi^{2}=8.01 ; d f=2 ; P=0.02\right)$, it was the lower rate that was recorded for $B$. fusca $\left(\chi^{2}=11.16 ; \mathrm{df}=2 ; \mathrm{P} \leq 0.0001\right)$, C. partellus $\left(\mathrm{X}^{2}=19.66 ; \mathrm{df}=2 ; \mathrm{P} \leq 0.0001\right)$ and $S$. calamistis $\left(\mathrm{X}^{2}=\right.$ $18.96 ; \mathrm{df}=2 ; \mathrm{P} \leq 0.0001)$ at that larval size group as compared to small and medium age groups.

\section{Survival, mortality, and cannibalism coupled with intraguild predation in pairing-species combination between fall armyworm and stemborers}

For all combinations, FAW survival rate was significantly higher than that of its corresponding competing species at all larval size groups: FAW+Bf (Fig. 2A, Table 2), FAW+Sc (Fig. 2B, Table 2) and FAW+Cp (Fig. 2C, Table 2). There was no significant difference for mortality within species in all combinations at small larval size group: FAW+Bf (Fig. 2D, Table 2), FAW+Sc (Fig. 2E, Table 2) and FAW+Cp (Fig. 2E, Table 2). However, the mortality of FAW was significantly higher in the pairing with $B$. fusca at medium and large larval size groups (Fig. 2D, Table 2), with $S$. calamistis at medium and large larval size groups (Fig. 2E, Table 2) and with C. partellus at medium and large larval size groups (Fig. 2F, Table 2). The cannibalism coupled with intraguild predation of stemborer species were significantly higher than that of FAW in all combinations at all larval size groups: FAW+Bf (Fig. 2G, Table 2), FAW+Sc (Fig. 2H, Table 2) and FAW+Cp (Fig. 2l, Table 2). 
Table 2

Results of GLM analysis comparing larval survival, mortality and cannibalism/intraguild predation between fall armyworm vs stemborer species in multi-species combinations at different development stages

\begin{tabular}{|c|c|c|c|c|c|c|c|c|c|}
\hline \multirow[t]{3}{*}{ Combinations } & \multicolumn{9}{|c|}{ Larvae development stages } \\
\hline & \multicolumn{3}{|l|}{ Small } & \multicolumn{3}{|c|}{ Medium } & \multicolumn{3}{|l|}{ Large } \\
\hline & LR & $d f$ & $P$ & LR & $d f$ & $P$ & LR & $d f$ & $P$ \\
\hline \multicolumn{10}{|l|}{ Survival } \\
\hline $\mathrm{FAW}+\mathrm{Bf}$ & 45.41 & 1 & $\leq 0.0001$ & 82.85 & 1 & $\leq 0.0001$ & 28.03 & 1 & $\leq 0.0001$ \\
\hline $\mathrm{FAW}+\mathrm{Sc}$ & 47.72 & 1 & $\leq 0.0001$ & 30.75 & 1 & $\leq 0.0001$ & 6.95 & 1 & 0.008 \\
\hline $\mathrm{FAW}+\mathrm{Cp}$ & 54.45 & 1 & $\leq 0.0001$ & 28.87 & 1 & $\leq 0.0001$ & 25.30 & 1 & $\leq 0.0001$ \\
\hline \multicolumn{10}{|l|}{ Mortality } \\
\hline $\mathrm{FAW}+\mathrm{Bf}$ & 0.22 & 1 & 0.63 & 4.6 & 1 & 0.04 & 6.05 & 1 & 0.01 \\
\hline $\mathrm{FAW}+\mathrm{Sc}$ & 0.86 & 1 & 0.35 & 6.73 & 1 & 0.009 & 10.35 & 1 & 0.001 \\
\hline $\mathrm{FAW}+\mathrm{Cp}$ & 0.02 & 1 & 0.88 & 11.82 & 1 & 0.0005 & 12.20 & 1 & 0.0004 \\
\hline \multicolumn{10}{|c|}{ Cannibalism/intraguild predation } \\
\hline $\mathrm{FAW}+\mathrm{Bf}$ & 82.47 & 1 & $\leq 0.0001$ & 49.11 & 1 & $\leq 0.0001$ & 26.95 & 1 & $\leq 0.0001$ \\
\hline $\mathrm{FAW}+\mathrm{Sc}$ & 62.41 & 1 & $\leq 0.0001$ & 28.73 & 1 & $\leq 0.0001$ & 10.35 & 1 & 0.001 \\
\hline$F A W+C p$ & 49.14 & 1 & $\leq 0.0001$ & 22.88 & 1 & $\leq 0.0001$ & 28.90 & 1 & $\leq 0.0001$ \\
\hline
\end{tabular}

Comparison of survival, mortality, and cannibalism and/or intraguild predation in single-versus pairingspecies combinations

For this comparison purpose, the survival, mortality, and cannibalism and/or intraguild predation rates were calculated for the overall larvae regardless of the species present in each test for pairing-species combinations. All stemborer single-species combinations exhibited a significant higher survival rate than their respective pairing-species combinations with FAW at all larval size groups (Fig. 3, small: LR = 202.62; $\mathrm{df}=6 ; \mathrm{P} \leq 0.0001$, medium: $\mathrm{LR}=146.56 ; \mathrm{df}=6 ; \mathrm{P} \leq 0.0001$ and large: $L R=127.78 ; \mathrm{df}=6 ; \mathrm{P} \leq$ $0.0001)$.

At small size group, stemborer single-species communities presented a higher mortality than their respective pairing-species combination with FAW $(L R=24.86 ; d f=6 ; P=0.0003)$. At medium size group, while FAW had lower mortality, $B$. fusca single-species had significantly higher mortality as compared to its pairing-species combination counterpart mortality $(L R=28.69 ; d f=6 ; P \leq 0.0001)$. At large size group, S. calamistis and $C$. partellus single-species combinations exhibited significantly lower mortalities as 
compared to the mortalities of their pairing-species combination counterparts $(L R=35.14 ; \mathrm{df}=6$; $P \leq$ 0.0001).

The cannibalism coupled with intraguild predation in pairing-species combination was significantly higher as compared to cannibalism in single-species combinations at all larval size groups (Fig. 3, small: $L R=349.81 ; \mathrm{df}=6 ; \mathrm{P} \leq 0.0001$, medium: $L R=356.83 ; \mathrm{df}=6 ; \mathrm{P} \leq 0.0001$ and large: $L R=246.41 ; \mathrm{df}=6 ; \mathrm{P}$ $\leq 0.0001)$.

\section{Life-time survival, relative growth rate, mortality, and cannibalism of fall armyworm and stemborers across larval instars in single-species combination}

Across larval instars, the three stemborers species presented similar survival evolution while significantly higher than those of FAW species from third to sixth instar (Fig. 4A, $\chi^{2}=308.17$; $d f=5 ; P=0.0001$ ). The FAW presented the greater relative growth rate as compared to those of stemborers at third and fourth instars with an optimum of $15 \mathrm{mg} /$ day (Fig. 4B).

The Fig. $4 \mathrm{C}$ present the evolution of mortality rate of the different species across larval development instars. At L1 instar, $S$. calamistis presented a high mortality rate as compared to other species $\left(\chi^{2}=\right.$ $26.93 ; \mathrm{df}=5 ; P=0.0001)$. However, at $L 5$ and $L 6$ instars, the mortality rate of FAW became significantly lower while those of stemborer species were still high $L 5\left(X^{2}=37.94 ; d f=3 ; P=0.02\right), L 6\left(X^{2}=98.23 ; d f=\right.$ $3 ; P=0.03$ ). The cannibalism rate (Fig. 4D) was significantly higher in FAW than in stemborer species from third to last instar, $L 3\left(X^{2}=56.7 ; d f=3 ; P=0.01\right), L 4\left(X^{2}=34.92 ; d f=3 ; P=0.002\right) L 5\left(X^{2}=95.78 ; d f=\right.$ $3 ; P=0.03)$ and $L 6\left(X^{2}=123.54 ; d f=3 ; P \leq 0.0001\right)$.

\section{Life-time survival, relative growth rate, mortality and cannibalism coupled with intraguild predation across larval development instars in pairing-species combinations}

In pairing-species combination between fall armyworm and stemborers, none of stemborer species survived at the last instar to pupate (Fig. 5A1-A3). The survival rate of either FAW or stemborers significantly decreased along larval development instars $\left(X^{2}=42.52 ; \mathrm{df}=5 ; \mathrm{P}=0.001\right)$ and the survival of FAW was significantly higher than those of stemborers in each combination $\left(\chi^{2}=57.13 ; d f=3 ; P=0.004\right)$. B. fusca and S. calamistis reached $0 \%$ at L4 instar and C. partellus at L5 instar while about $10 \%$ of FAW survived at last instar to pupate. The growth rate of stemborer species did not reach the optimum before they disappeared in the combinations (Fig. 5B1-B3). The optimum of FAW growth rate ranged from 40 to $50 \mathrm{mg} /$ day across the different combinations and it has mostly decreased after stemborer species were no longer present in the combinations (Fig. 5B1-B3). In each pairing-species combination, the mortality rate of stemborers was significantly $\left(X^{2}=32.34 ; \mathrm{df}=3 ; \mathrm{P}=0.001\right)$ higher than those of FAW along larval development instars before the optimum and thereafter, the mortality rate of FAW come over those of stemborer species (Fig. 5C1-C3). on the other hand, the cannibalism coupled with intra-guild predation of stemborers in each combination was significantly higher than those of FAW along larval development 
instars $\left(X^{2}=54.21 ; d f=3 ; P \leq 0.0001\right)$. However, when they finished in the system, the cannibalism of FAW presented exponential trend (Fig. 5D1-D3).

\section{Discussion}

The polyphagous feeding habitat (Montezano et al. 2018), voracity (Wan et al. 2021), the high potential economic loss in crops (Wang et al. 2020) and the recent invasion in Africa (Goergen et al. 2016) of fall armyworm have created significant interest in its potential interactions with maize stemborer species. Our results indicated that FAW exhibited cannibalism to a larger degree than stemborers species, especially in the late instars. The large degree of cannibalism in FAW may contribute to their relatively lower survival in single species cohorts. The cannibalistic behaviour of FAW has already been well documented, both in laboratory and under field conditions (Chapman et al. 2000; Goussain et al. 2002). In the present study when the larvae were followed from neonate to last development stage, the cannibalism was observed mostly from 3rd instar with a maximum level at 5th and 6th instars indicating the positive correlation between the cannibalism phenomenon and the aggressivity of the insect when becoming large (Bentivenha et al. 2016b). Chilcutt (2006) and Horner et al. (2009) have reported that in Noctuid insects, cannibalism is dependent on the insect development instar with a tendency to more frequently occur in larger than smaller larvae. In addition to the high cannibalism rate recorded in FAW as compared to other species, there also seems to be some intrinsic mortality in FAW, especially in the largest instar. Several studies have shown that larvae which end up practicing cannibalism may have high mortality by suffering injuries and death acquiring pathogens and parasites, having subsequent reduction in fitness which might differ between native and invasive insect species (Bentivenha et al. 2016; Chapman et al. 1999a,b; Rudolf \& Antonovics 2007).

Invasive species are generally less frequently infected in introduced environment as compared to native conspecific populations (Torchin \& Mitchell 2004). Successful introduced species often invade without their native parasites and accumulate relatively few new ones in the invaded areas. This suggest that costs- and benefits of cannibalism differ in native and invaded area depending on whether they experience less or more parasites and pathogens in these areas. In the other hand, it has been reported that FAW cannibalism rates were around $18 \%$, when confined to maize seedlings and can increase up to $34 \%$ in case of limited food and even reach $100 \%$ when the larvae are confined in Petri dishes (Bentivenha et al. 2016; Raffa 1987). The suitability of food in terms of quality on which the insect larvae were reared is also a source of cannibalism increase. Therefore, it would be interesting to study how costbenefits of cannibalism/intraguild predation could differ depending on host plant species.

In interspecific interactions, the higher cannibalism in FAW turns however to competitive advantage when they cohabit with stemborer species. Cannibalism/intraguild predation is higher on the stemborers, and survival is always higher for FAW. The FAW larvae might possess defence mechanism in detriment of other species. Bentivenha et al. (2017a) studied intraspecific interactions of FAW larvae and reported that they exhibited either high attack (head touching) or defense (recoiling) as the prevalent movement and that the frequency of these movements increased with larval development because of their increased 
interaction with other larvae when they become bigger and more mobile. These results suggest that there is a great chance that FAW can prevail over these other species and colonize the niche (Bentivenha et al. 2016b; Bentivenha et al. 2017b), when these species occur in maize fields (on plants). Intraguild studies of FAW and $H$. zea showed further advantage of FAW in interaction against $H$. zea in morphological characteristic such as integument or mandible architecture (Bentivenha et al. 2016a), which also could explain the success of FAW during intraguild competition. The intrinsic cannibal character of FAW might prepare the species to a high cost of fight within themselves (actions of defence and attack) in the situation of conspecific cannibalism which explain the lower relative growth rate. In interspecific competition, the actions of the co-existing stemborers which probably go into defense behaviour rather attack, inflict lower fight cost to FAW by the lack of attack actions. Therefore, FAW take the advantage by reducing the cannibalism on their conspecific and concentrate on intraguild predation on their heterospecific species where it is more easy to feed on stemborer larvae with less energy invested, explaining the great relative growth rate gained when reared together with stemborer species than when reared lonely as single species. Arnott \& Elwood (2009) have studied those variations of the weight by assessing fighting ability in animal contests and reported that the gain of the weight of the superior from the competition is positively correlated to the contest duration and the cost or intensity of the fight. The competition between FAW and stemborers may be short duration with low-cost than between FAW conspecific species.

The optimum of FAW growth rate ranged from 40 to $50 \mathrm{mg} /$ day in cannibalism coupled with intraguild predation with stemborer species while when reared lonely as single species, the growth rate reached an optimal of $30 \mathrm{mg} /$ day only. These results are in contradiction with other studies in the literature (e.g. Bentivenha et al. 2016a,b; Ongaratto et al. 2021), where the weight of FAW reared alone as single species and not in competition with other species was significantly greater than the weight of those that surviving the competition with other heterospecific species. However, in the present study, the competition was asymmetric that favour FAW because, while FAW exhibited simultaneously defense and attack behaviour, stemborer species might exhibit only defense behaviour.

The higher intraguild predation of FAW on stemborer species when they are forced to co-habitat indicates a potential competitive advantage of FAW and could be a factor explaining its success as an invasive pest species. However, this analysis needs to be done at large scale as a complex system because other parameters such as agricultural landscape (Bentivenha et al. 2016a), the food quality of the host plant and larval behaviour (Dial \& Adler 1990) may influence also intraguild interactions. Intraguild predation may be an important factor during invasion to decrease competition from other species, but in the present study, it does not seem to lead to a higher absolute survival rate of FAW, only a relatively better survival in comparison to the other species. This can be due to that FAW reverses cannibalism behaviour in detriment of intraguild predation when the heterospecific species disappears/is eradicated from the system when FAW are in the later instars. Linked to this great competitive advantage of FAW over stemborer species highlighted in this study, FAW tend to dominate stemborers in maize cropping systems where they co-habituate with a possible displacement of stemborers by FAW elsewhere; for example, to other cereal (Hailu et al. 2021; Sokame et al. 2021a). Historical data of stemborer infestations compared 
to the recent evaluations in maize and sorghum cropping systems in Uganda showed a significant decline of the infestations in maize fields in detriment to sorghum fields from 2016, suggestion an early arrival of fall armyworm in Uganda, indicating a possible displacement of stemborer from maize onto sorghum (Hailu et al. 2021). Furthermore, through intense intraguild predation, fall armyworm can reduce the population density and impact of stemborer guild members in maize fields, as the larvae preferred to feed on stemborers rather than their conspecific in interspecific communities. However, if the guild of fall armyworm is to contribute to the suppression of stemborer species population in the context of integrated pest management (IPM) programme, then it necessary that its impact on those stemborers is reliably assessed at an appropriate ecological scale so that the impact on the population dynamics of the pest can be quantified and integrated into decision-making processes for management.

Overall, interaction among FAW and stemborer species in the case of this study affect their survival and FAW gain competitive advantage in intraguild interaction with stemborer species in detriment of cannibalism with their conspecifics. This gives an advantage of FAW over maize stemborers resulting of an overall reduction in stemborer density generally observed in maize fields in Kenya at the beginning of the season (Sokame et al. 2021a), a displacement of some of them to other cereals in Uganda (Hailu et al. 2021). However, the specificity of FAW to feed on leaves and stemborers to plant stems in late instars might result in the co-existence fall armyworm with stemborer species in maize agroecological zones (Sokame et al. 2020, 2021b). Therefore, the invasion of FAW in Africa constitutes an additional pest to crops in agroecosystems that need to be considered within the context of integrated pest management strategies.

\section{Declarations}

\section{Authors contributions}

BMS, P-AC, PA, and GKKdesigned the studies. BMS, and BM collected the data. BMS analysed the data and wrote the manuscript. All authors reviewed and approved the manuscript before submission.

\section{Acknowledgements}

This research was funded by "Institut de Recherche pour le Développement" (IRD)-France through Noctuid Stemborers Biodiversity (NSBB) project (grant number: B4405B), Swedish Research Network Grant (grant number: 2019-04267) and Integrated pest management strategy to counter the threat of invasive fall armyworm to food security in eastern Africa (FAW-IPM) (grant number: DCI-FOOD/2017/) financed under European Union. The authors also gratefully acknowledge the financial support for this research by the following organizations and agencies: the Swedish International Development Cooperation Agency (Sida); the Swiss Agency for Development and Cooperation (SDC); the Federal Democratic Republic of Ethiopia; and the Government of the Republic of Kenya. The views expressed herein do not necessarily reflect the official opinion of the donors.

\section{Compliance with ethical standards}


Conflicts of interest: The authors declare that they have no conflicts of interest.

Ethical approval: This research complied with all local and national standards for ethical conduct in research. This research did not involve vertebrates or humans, and thus, no IRB approvals were needed.

\section{References}

1. Andow DA, Farias JR, Horikoshi RJ, Bernardi D, Nascimento AR, Celso O (2015) Dynamics of cannibalism in equal-aged cohorts of Spodoptera frugiperda. Ecol Entomol 40:229-236. https://doi.org/10.1111/een.12178

2. Arnott G, Elwood RW (2009) Assessment of fighting ability in animal contests. Anim Behav 77:9911004. https://doi.org/10.1016/j.anbehav.2009.02.010

3. Benelli G (2015) Should I fight or should I flight? How studying insect aggression can help integrated pest management. Pest Manag Sci 71:885-892. https://doi.org/10.1002/ps.3974

4. Bentivenha JP, Montezano D, Hunt TE, Baldin EL, Peterson JA, Victor V, Pannuti LE, Velez AM, PaulaMoraes SV (2017a) Intraguild interactions and behavior of Spodoptera frugiperda and Helicoverpa spp. on maize. Pest Manag Sci 73:2244-2251. https://doi.org/10.1002/ps.4595

5. Bentivenha José PF, Baldin ELL, Montezano DG, Hunt TE, Paula-Moraes SV (2017b) Attack and defense movements involved in the interaction of Spodoptera frugiperda and Helicoverpa zea (Lepidoptera: Noctuidae). J Pest Sci 90:433-445. https://doi.org/10.1007/s10340-016-0802-3

6. Bentivenha JPF, Baldin ELL, Hunt TE, Paula-Moraes SV, Blankenship EE (2016a) Intraguild competition of three noctuid maize pests. Environ Entomol 45:999-1008.

https://doi.org/10.1093/ee/nvw068

7. Bentivenha JPF, Paula-Moraes SV, Baldin ELL, Specht A, da Silva IF, Hunt TE (2016b) Battle in the New World: Helicoverpa armigera versus Helicoverpa zea (Lepidoptera: Noctuidae). PLoS ONE 11:e0167182. https://doi.org/10.1371/JOURNAL.PONE.0167182

8. Bonhof MJ, Overholt WA (2001) Impact of solar radiation rainfall and cannibalism on disappearance of maize stemborers in Kenya. Insect Sci Appl 21:403-407. https://doi.org/10.1017/s1742758400008523

9. Briffa M, Elwood RW (2004) Use of energy reserves in fighting hermit crabs. Proc Royal Soc B 271:379. https://doi.org/10.1098/RSPB.2003.2633

10. CAB International (2017) How to identify ... fall armyworm. Poster. Plantwise, http://www.plantwise.org/FullTextPDF/2017/20177800461.pdf (2017) (Date of access: 23/11/2018). https://www.cabi.org/isc/fallarmyworm

11. Cameron TC, Wearing HJ, Rohani P, Sait SM (2007) Two-species asymmetric competition: effects of age structure on intra- and interspecific interactions. J Anim Ecol 76:83-93. https://doi.org/10.1111/j.1365-2656.2006.01185.x

12. Chapman JW, Williams T, Martínez AM, Cisneros J, Caballero P, Cave RD, Goulson D (2000) Does cannibalism in Spodoptera frugiperda (Lepidoptera: Noctuidae) reduce the risk of predation? Behav 
Ecol Sociobiol 48:321-327. https://doi.org/10.1007/s002650000237

13. Chapman JW, Williams T, Escribano A, Caballero P, Cave RD, Goulson D (1999a) Age-related cannibalism and horizontal transmission of a nuclear polyhedrosis virus in larval Spodoptera frugiperda. Ecol Entomol 24:268-275

14. Chapman JW, Williams T, Escribanoc A, Caballero P, Cave RD (1999b) Fitness consequences of cannibalism in the fall armyworm, Spodoptera frugiperda. Behav Ecol 10:298-303. https://doi.org/10.1093/beheco/10.3.298

15. Chilcutt CF (2006) Cannibalism of Helicoverpa zea (Lepidoptera: Noctuidae) from Bacillus thuringiensis (Bt) transgenic corn versus Non-Bt corn. J Econ Entomol 99:728-732. https://doi.org/10.1093/jee/99.3.728

16. Cruz I, Turpin FT (1983) Yield impact of larval infestations of the Fall Armyworm Spodoptera frugiperda (J. E. Smith) to Midwhorl Growth Stage of Corn1. J Econ Entomol 76:1052-1054. https://doi.org/10.1093/jee/76.5.1052

17. Dial Cl, Adler PH (1990) Larval behavior and cannibalism in Heliothis zea (Lepidoptera: Noctuidae). Ann Entomol Soc Am 83: 258-263. https://doi.org/10.1093/aesa/83.2.258

18. Elgar M, Crespi J (1992) Cannibalism: ecology and evolution among diverse taxa. Oxford University Press, Oxford, United Kingdom

19. Goergen G, Kumar PL, Sankung SB, Togola A, Tamò M (2016) First report of outbreaks of the fall armyworm Spodoptera frugiperda (J E Smith) (Lepidoptera, Noctuidae), a new alien invasive pest in West and Central Africa. PLoS ONE 11:e0165632. https://doi.org/10.1371/journal.pone.0165632

20. Goussain MM, Moraes JC, Carvalho JG, Nogueira NL, Rossi EML (2002) Effect of silicon application on corn plants upon the biological development of the fall Armyworm Spodoptera frugiperda (J.E. Smith) (Lepidoptera: Noctuidae). Neotrop Entomol 31:305-310

21. Gurevitch J, Morrow LL, Wallace A, Walsh JS (1992) A Meta-Analysis of Competition in Field Experiments. Am Nat 140:539-572

22. Hailu G, Niassy S, Bässler T, Ochatum N, Studer C, Salifu D, Agbodzavu MK, Khan ZR, Midega C, Subramanian S (2021) Could fall armyworm, Spodoptera frugiperda (J. E. Smith) invasion in Africa contribute to the displacement of cereal stemborers in maize and sorghum cropping systems. Int $\mathrm{J}$ Trop Insect Sci 41:1753-1762

23. Holloway JD (1998) Noctuidae; In African Cereal Stem Borers: Economic importance, taxonomy, natural enemies and control, Polaszek A. (ed), Wallingford, UK (pp. 79-86)

24. Holt RD, Polis GA (1997) A Theoretical Framework for Intraguild Predation. Am Nat 149:745-764

25. Horner TA, Dively GP, Herbert DA (2009) Development, Survival and Fitness Performance of Helicoverpa zea (Lepidoptera: Noctuidae) in MON810 Bt Field Corn. J Econ Entomol 96:914-924. https://doi.org/10.1603/0022-0493-96.3.914

26. Kassie M, Wossen T, De Groote H, Tefera T, Sevgan S, Balew S (2020) Economic impacts of fall armyworm and its management strategies: evidence from southern Ethiopia. Eur Rev Agric Econ 47:1473-1501. https://doi.org/10.1093/erae/jbz048 
27. Kelly CD, Godin JJ (2001) Predation Risk Reduces Male-Male Sexual Competition in the Trinidadian Guppy (Poecilia reticulata). Behav Ecol Sociobiol 51:95-100

28. Kfir R, Overholt WA, Khan ZR, Polaszek A (2002) Biology and management of economicaly important lepidopteran cereal stem borers in Africa. Annu Rev Entomol 47:701-731. https://doi.org/. DOI

29. Krüger W, van den Berg J, van Hamburg H (2008) The relative abundance of maize stem borers and their parasitoids at the Tshiombo irrigation scheme in Venda, South Africa. S Afr J Plant Soil 25:144-151. https://doi.org/10.1080/02571862.2008.10639910

30. Montezano DG, Specht A, Sosa-Gómez DR, Roque-Specht VF, Sousa-Silva JC, Paula-Moraes SV, Peterson JA, Hunt TE (2018) Host Plants of Spodoptera frugiperda (Lepidoptera: Noctuidae) in the Americas. Afr Entomol 26:286-300. https://doi.org/10.4001/003.026.0286

31. Morrill WL, Greene GL (1973) Distribution of Fall Armyworm larvae. 1. Regions of field corn plants infested by larvae. Environ Entomol 2:195-198

32. Ntiri ES, Calatayud PA, Van Den Berg J, Schulthess F, Le Ru BP (2016) Influence of temperature on intra- And interspecific resource utilization within a community of lepidopteran maize stemborers. PLoS ONE 11:e148735. https://doi.org/10.1371/journal.pone.0148735

33. Ntiri ES, Calatayud PA, Van den Berg J, Le Ru BP (2017) Density dependence and temporal plasticity of competitive interactions during utilisation of resources by a community of lepidopteran stemborer species. Entomol Exp Appl 162:272-283. https://doi.org/10.1111/eea.12514

34. Ojeda-Avila T, Woods HA, Raguso RA (2003) Effects of dietary variation on growth, composition, and maturation of Manduca sexta (Sphingidae: Lepidoptera). J Insect Physiol 49:293-306. https://doi.org/10.1016/S0022-1910(03)00003-9

35. Ong'amo G, Le Rü B, Dupas S, Moyal P, Calatayud P-A, Silvain J-F (2006) Distribution, pest status and agro-climatic preferences of lepidopteran stem borers of maize in Kenya. Ann Soc Entomol Fr 42:171-177. https://doi.org/10.1080/00379271.2006.10700620

36. Ongaratto S, Baldin EL, Hunt TE, Montezano DG, Robinson EA, Santos MC (2021) Effects of intraguild interactions on Anticarsia gemmatalis and Chrysodeixis includens larval fitness and behavior in soybean. Pest Manag Sci 77:2939-2947. https://doi.org/10.1002/PS.6330

37. Polaszek A (1998) African Cereal Stem Borers: Economic Importance, Natural Enemies and Control. CAB International, Wallingford, Oxon, UK

38. Polis GA (1981) The evolution and dynamics of intraspecific predation. Annu Rev Ecol Evol Syst 12:225-251

39. Polis GA, Holt RD (1992) Intraguild predation: The dynamics of complex trophic interactions. Trends Ecol Evol 7:151-154. https://doi.org/10.1016/0169-5347(92)90208-S

40. R Core Team (2018) R: A language and environment for statistical computing. Vienna, Austria: $R$ Foundation for Statistical Computing. Retrieved from https://www.R-project.org/

41. Raffa KF (1987) Influence of host plant on deterrence by Azadirachtin of feeding by fall armyworm larvae (Lepidoptera: Noctuidae). J Econom Entomol 80:384-387.

https://doi.org/10.1093/jee/80.2.384

Page 15/18 
42. Rasekh A, Osawa N (2020) Direct and indirect effect of cannibalism and intraguild predation in the two sibling Harmonia ladybird beetles. Ecol Evol 10:5899-5912. https://doi.org/10.1002/ece3.6326

43. Richardson $M$, Mitchell $R$, Reagel $P$, Hanks $L$ (2010) Causes and consequences of cannibalism in noncarnivorous insects. Annu Rev Entomol 55:39-53. https://doi.org/10.1146/annurev-ento-112408085314

44. Rudolf VH, Antonovics J (2007) Disease transmission by cannibalism: rare event or common occurrence? Proc Royal Soc B 274:1205. https://doi.org/10.1098/RSPB.2006.0449

45. Seshu-Reddy KV (1998) Maize and sorghum: East Africa. In African Cereal Stem Borers: Economic Importance, Taxonomy, Natural Enemies and Control (Edited by A. Polaszek). CAB International. Wallingford, Oxon.

46. Sokame BM, Malusi P, Subramanian S, Kilalo DC, Juma G, Calatayud PA (2022) Do the invasive Fall Armyworm, Spodoptera frugiperda (Lepidoptera: Noctuidae), and the maize lepidopteran stemborers compete when sharing the same food? Phytoparasitica 50:21-34. https://doi.org/10.1007/s12600021-00952-6

47. Sokame BM, Musyoka B, Obonyo J, Rebaudo F, Abdel-rahman EM, Subramanian S, Kilalo DC, Juma G, Calatayud PA (2021a) Impact of an exotic invasive pest, Spodoptera frugiperda (Lepidoptera : Noctuidae), on resident communities of pest and natural enemies in maize fields in Kenya. Agronomy 11:1074. https://doi.org/https://doi.org/10.3390/agronomy11061074

48. Sokame BM, Tonnang HEZ, Subramanian S, Bruce AY, Dubois T, Ekesi S, Calatayud PA (2021b) A system dynamics model for pests and natural enemies interactions. Sci Rep 11:1-14. https://doi.org/10.1038/s41598-020-79553-y

49. Sokame BM, Rebaudo F, Malusi P, Subramanian S, Kilalo DC, Juma G, Calatayud PA (2020) Influence of temperature on the interaction for resource utilization between Fall Armyworm, Spodoptera frugiperda (Lepidoptera: Noctuidae), and a community of lepidopteran maize stemborers larvae. Insects 11:73. https://doi.org/10.3390/insects11020073

50. Takizawa T, Snyder WE (2011) Cannibalism and intraguild predation of eggs within a diverse predator assemblage. Environ Entomol 40:8-14

51. Tefera T (2004) Lepidopterous stem borers of sorghum and their natural enemies in eastern Ethiopia. Trop Sci 44:128-130. https://doi.org/10.1002/ts.153

52. Torchin ME, Mitchell CE (2004) Parasites, pathogens, and invasions by plants and animals. Front Ecol Environ 2:183-190

53. Van den Berg J (1997) Economy of stem borer control in sorghum. ARC-Crop protection Series no 2, Potchefstroom, South Africa, $p p-4$.

54. Van den Berg J, Van Rensburg JBJ, Pringle KL (1991) Comparative injuriousness of Busseola fusca (Lepidoptera: Noctuidae) and Chilo partellus (Lepidoptera: Pyralidae) on grain sorghum. Bull Entomol Res 81:137-142. https://doi.org/10.1017/S0007485300051191

55. Wagner JD, Wise DH (1996) Cannibalism regulates densities of young wolf spiders: Evidence from field and laboratory experiments. Ecology 77:639-652. https://doi.org/10.2307/2265637 
56. Wan J, Huang C, Li C, Zhou H, Ren Y, Li Z, Xing L, Zhang B, Qiao X, Liu B, Liu C, Xi Y, Liu W, Wang W, Qian W, Mckirdy S, Wan F (2021) Biology, invasion and management of the agricultural invader: Fall armyworm, Spodoptera frugiperda (Lepidoptera: Noctuidae). J Integr Agric 20:646-663. https://doi.org/10.1016/S2095-3119(20)63367-6

57. Wang W, He P, Zhang Y, Liu T, Jing X, Zhang S (2020) The Population Growth of Spodoptera frugiperda on six cash Crop species and implications for its occurrence and damage potential in China. Insects 11:639. https://doi.org/10.3390/INSECTS11090639

\section{Figures}

\section{Figure 1}

Survival (A), mortality (B) and cannibalism rates (C) of Spodoptera frugiperda (FAW), Busseola fusca (Bf), Sesamia calamistis (Sc), and Chilo partellus ( $\mathrm{Cp}$ ) in single-species combinations at different larval stages: small size (neonate to second instar), medium size (third to fourth instar) and large size (fifth to sixth instar). Means ( $\pm S E)$ with different letters are significantly different, determined using Tukey's multiple comparisons tests performed with Ismeans R package, following generalized linear model (GLM) with negative binomial procedure (comparison between species, lower case letters) and Kruskal-Wallis nonparametric procedure with dunn.test $\mathrm{R}$ package (comparison between larval sizes of a given species, upper case letter).

\section{Figure 2}

Survival (A-C), mortality (D-F) and cannibalism coupled with intraguild predation rates (G-I) of Spodoptera frugiperda (FAW), Busseola fusca (Bf), Sesamia calamistis (Sc), and Chilo partellus (Cp) in pairingspecies combinations at different larval stages: small size (neonate to second instar), medium size (third to fourth instar) and large size (fifth to sixth instar). Means ( $\pm S E)$ with different letters are significantly different, determined using Tukey's multiple comparisons tests performed with Ismeans R package, following generalized linear model (GLM) with negative binomial procedure.

\section{Figure 3}


Survival (A), mortality (B) and cannibalism coupled with intraguild predation rates (C) of all larvae regardless of the species between single-species and pairing-species combinations at different larval stages: small size (neonate to second instar), medium size (third to fourth instar) and large size (fifth to sixth instar). Statistical comparisons were only considered between single- and corresponding multispecies pairings. Means $( \pm S E)$ were compared using Tukey's comparisons tests performed using Ismeans R package, following generalized linear model (GLM) with negative binomial procedure. Spodoptera frugiperda (FAW), Busseola fusca (Bf), Sesamia calamistis (Sc), and Chilo partellus (Cp).

\section{Figure 4}

Evolution of survival (A), relative growth rate (B), mortality (C) and cannibalism rates (D) of Spodoptera frugiperda (FAW), Busseola fusca (Bf), Sesamia calamistis (Sc), and Chilo partellus (Cp) in single-species combinations from neonate to last instar larvae.

\section{Figure 5}

Evolution of survival (A1-A3), relative growth rate (B1-B3), mortality (C1-C3) and cannibalism coupled with intraguild predation rates (D1-D3) of Spodoptera frugiperda (FAW), Busseola fusca (Bf), Sesamia calamistis (Sc), and Chilo partellus $(\mathrm{Cp})$ in pairing-species combinations from neonate to last instar larvae. 